\title{
AUTOMOTIVE APPLICATIONS OF EVOLVING TAKAGI-SUGENO-KANG FUZZY MODELS
}

\author{
UDC 681.5
}

\section{Radu-Emil Precup, Stefan Preitl, Claudia-Adina Bojan-Dragos, Mircea-Bogdan Radac, Alexandra-Iulia Szedlak-Stinean, Elena-Lorena Hedrea, Raul-Cristian Roman}

Politehnica University of Timisoara, Dept. Automation and Applied Informatics, Romania

\begin{abstract}
This paper presents theoretical and application results concerning the development of evolving Takagi-Sugeno-Kang fuzzy models for two dynamic systems, which will be viewed as controlled processes, in the field of automotive applications. The two dynamic systems models are nonlinear dynamics of the longitudinal slip in the Antilock Braking Systems (ABS) and the vehicle speed in vehicles with the Continuously Variable Transmission (CVT) systems. The evolving Takagi-Sugeno-Kang fuzzy models are obtained as discrete-time fuzzy models by incremental online identification algorithms. The fuzzy models are validated against experimental results in the case of the $A B S$ and the first principles simulation results in the case of the vehicle with the CVT.
\end{abstract}

Key Words: Automotive Applications, Anti-lock Braking Systems, Continuously Variable Transmission Systems, Dynamics, Evolving Takagi-SugenoKang Fuzzy Models

\section{INTRODUCTION}

The main property of the evolving Takagi-Sugeno-Kang fuzzy models, which gives them advantages over other fuzzy ones, consists in computing the rule bases by a learning process, that is, by continuous online rule base learning as shown in the classical and recent papers exemplified by [1-10]. The Takagi-Sugeno-Kang fuzzy models are obtained by evolving the model structure and parameters in terms of online identification algorithms. The adding mechanism in the structure of online identification algorithms plays an

\footnotetext{
Received May 05, 2017 / Accepted June 20, 2017

Corresponding author: Radu-Emil Precup

Politehnica University of Timisoara, Department of Automation and Applied Informatics, Bd. V. Parvan 2, 300223 Timisoara, Romania

E-mail: radu.precup@upt.ro 
important role because it adds or removes new local models; the evolving structure and parameters are, therefore, ensured.

A well-acknowledged classification of the online identification algorithms oriented on the evolving Takagi-Sugeno-Kang fuzzy models is presented in [11]. This classification highlights three categories of online identification algorithms, i.e., II and III, briefly pointed out as follows. Category I of the adaptive algorithms starts with the initial structure of the Takagi-Sugeno-Kang fuzzy model, given by other algorithms or by the experience of the specialist in the modeling or operation of the nonlinear dynamic system being modeled. The number of space partitions/clusters does not change over time, and these algorithms adapt just the parameters of the membership functions and the local models. Category II is represented by the incremental algorithms, which are applied in this paper, with examples referred to as the widely applied algorithms RAN [12, 13], SONFIN [14, 15], NeuroFAST [16, 17], DENFIS [18, 19], SCFNN [20, 21], eTS [22], [23], FLEXFIS [24, 25], and PANFIS [26]. These algorithms implement just adding mechanisms. Category III consists of evolving algorithms. Besides the adding mechanism, Category III also implements removing and some of these algorithms merging and splitting mechanisms as well.

This paper presents a part of the recent results obtained by the Process Control group of the Politehnica University of Timisoara, Romania, in the development of evolving Takagi-Sugeno-Kang fuzzy models obtained by online incremental algorithms. The paper continues the work carried out in [27] concerning the presentation of real-world applications of the evolving Takagi-Sugeno-Kang fuzzy models that describe the dynamics of nonlinear systems in crane systems [28, 29], pendulum systems [30, 31], prosthetic hand fingers [32] and twin rotor aerodynamic systems [33]. The main difference with respect to [27] is that this paper applies incremental online identification algorithms to the derivation of evolving Takagi-Sugeno-Kang fuzzy models for other process applications in order to characterize their dynamics. Two automotive applications are treated in this paper: one concerns modeling of the longitudinal slip dynamics in the Anti-lock Braking Systems (ABSs) Laboratory [34], while the other one models the vehicle speed dynamics in the vehicles with the Continuously Variable Transmission (CVT) systems.

The evolving fuzzy models presented in this paper and the online identification algorithms are important because they are developed with the intention to be used in the process control. Relevant process and control applications are presented in [35-43], with both crisp and fuzzy models. However, the online identification algorithms must be adapted accordingly in order to cope with the specific nonlinear elements and operating conditions of these processes [44-50].

The paper is organized as follows: an overview of incremental online identification algorithms is presented in the next section. Several results related to the derivation of the evolving Takagi-Sugeno-Kang fuzzy models for the two automotive applications are given in Section 3. The examples of fuzzy models are validated against experimental results in case of the ABS and the first principles simulation results in the case of vehicle with the CVT. The conclusions are outlined in Section 4. 


\section{OVERVIEW ON INCREMENTAL ONLINE IDENTIFICATION ALGORITHMS}

The basic version of incremental online identification algorithm is implemented using the theoretical aspects described in [27] and [33] in terms of the software support of eFS Lab presented in [51] and [52]. The flowchart of the basic version of incremental online identification algorithm is presented in Fig. 1, where TSK is the abbreviation of TakagiSugeno-Kang. This algorithm proceeds in accordance with the following steps described as follows and also given in [27] and [33]:

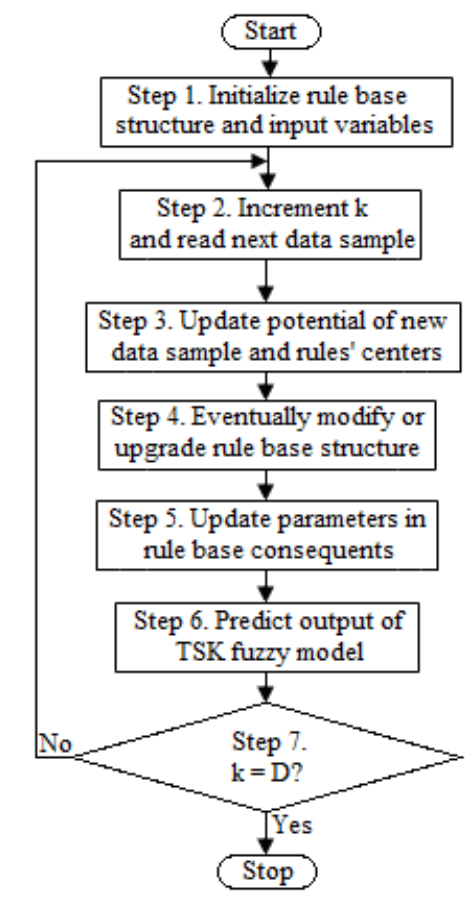

Fig. 1 Flowchart of basic version of incremental online identification algorithm [27]

Step 1. The rule base structure is initialized by setting all the parameters of rule antecedents so as to initially contain just one rule, namely $n_{R}=1$, where $n_{R}$ is the number of rules. The subtractive clustering is next applied to compute the parameters of the evolving Takagi-Sugeno-Kang fuzzy models using first data point $\mathbf{p}_{1}$, with the general expression [22] of data point $\mathbf{p}$ in the input-output data set at discrete time step $k$, with notation $\mathbf{p}_{k}$ :

$$
\begin{aligned}
& \mathbf{p}_{k}=\left[\begin{array}{lll}
p_{k}^{1} & p_{k}^{2} & \ldots \\
p_{k}^{n+1}
\end{array}\right]^{T},
\end{aligned}
$$

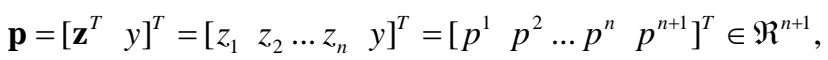

where $T$ stands for matrix transposition. 
The expression of the input-output data set is:

$$
\left\{\mathbf{p}_{k} \mid k=1 \ldots D\right\} \subset \mathfrak{R}^{n+1},
$$

where $D$ is the number of input-output data points or data points or data samples or samples.

The rule base of Takagi-Sugeno-Kang fuzzy models with affine rule consequents, also called the first-order Sugeno fuzzy inference systems in some software programs and toolboxes implementations, is:

Rule $i$ : IF $z_{1} \operatorname{IS} L T_{i 1}$ AND $\ldots$ AND $z_{n}$ IS $L T_{i n}$ THEN $y_{i}=a_{i 0}+a_{i 1} z_{1}+\ldots+a_{i n} z_{n}, i=1 \ldots n_{R}$,

where $z_{j}, j=1 \ldots n$, are input variables, $n$ is the number of input variables, $L T_{i j}, i=1 \ldots$ $n_{R}, j=1 \ldots n$, are input linguistic terms, $y_{i}$ is the output of the local model in the rule consequent of the rule with index $i, i=1 \ldots n_{R}$, and $a_{i l}, i=1 \ldots n_{R}, l=0 \ldots n$, are the parameters in the rule consequents.

A more flexible input-output map of the Takagi-Sugeno-Kang fuzzy models can be ensured if other expressions are included in the rule consequents. However, this complicates the parameter estimation specific to the rule consequents.

The Takagi-Sugeno-Kang fuzzy model structure considered in this paper includes the algebraic product t-norm as an AND operator and the weighted average defuzzification method. This leads to the expression of output $y$ of the Takagi-Sugeno-Kang fuzzy model:

$$
\begin{aligned}
& y=\left[\sum_{i=1}^{n_{R}} \tau_{i} y_{i}\right] /\left[\sum_{i=1}^{n_{R}} \tau_{i}\right]=\sum_{i=1}^{n_{R}} \lambda_{i} y_{i}, y_{i}=\left[\begin{array}{ll}
1 & \mathbf{z}^{T}
\end{array}\right] \boldsymbol{\pi}_{i}, \\
& \lambda_{i}=\tau_{i} /\left[\sum_{i=1}^{n_{R}} \tau_{i}\right], i=1 \ldots n_{R},
\end{aligned}
$$

where the firing degree of rule $i$ and the normalized firing degree of rule $i$ are $\tau_{i}(\mathbf{z})$ and $\lambda_{i}$, respectively, and the parameter vector of rule $i$ is $\pi_{i}, i=1 \ldots n_{R}$. The expression of the firing degree is:

$$
\tau_{i}(\mathbf{z})=\operatorname{AND}\left(\mu_{i 1}\left(z_{1}\right), \mu_{i 2}\left(z_{2}\right), \ldots, \mu_{i n}\left(z_{n}\right)\right)=\mu_{i 1}\left(z_{1}\right) \cdot \mu_{i 2}\left(z_{2}\right) \cdot \ldots \cdot \mu_{i n}\left(z_{n}\right), i=1 \ldots n_{R},
$$

and the expression of the parameter vector is:

$$
\boldsymbol{\pi}_{i}=\left[\begin{array}{llll}
a_{i 0} & a_{i 1} & \ldots & a_{i n}
\end{array}\right]^{T}, i=1 \ldots n_{R} .
$$

The other parameters specific to the incremental online identification algorithm are initialized as follows using [22]:

$$
\begin{aligned}
& \hat{\boldsymbol{\theta}}_{1}=\left[\left(\boldsymbol{\pi}_{1}^{T}\right)_{1}\left(\boldsymbol{\pi}_{2}^{T}\right)_{1} \ldots\left(\boldsymbol{\pi}_{n_{R}}^{T}\right)_{1}\right]^{T}=\left[\begin{array}{ll}
0 & 0 \ldots 0
\end{array}\right]^{T}, \mathbf{C}_{1}=\Omega \mathbf{I}, r_{s}=0.4, \\
& k=1, n_{R}=1, \mathbf{z}_{1}^{*}=\mathbf{z}_{k}, P_{1}\left(\mathbf{p}_{1}^{*}\right)=1,
\end{aligned}
$$

where $\mathbf{C}_{k} \in \mathfrak{R}^{n_{R}(n+1) \times n_{R}(n+1)}$ is the fuzzy covariance matrix related to the clusters, $\mathbf{I}$ is the $n_{R}(n+1)^{\text {th }}$ order identity matrix, $\Omega=$ const, $\Omega>0$, is a large number, $\hat{\boldsymbol{\theta}}_{k}$ is an estimation of the parameter vector in the rule consequents at discrete time step $k$, and $r_{s}, r_{s}>0$, is the 
spread of all Gaussian input membership functions $\mu_{i j}, i=1 \ldots n_{R}, j=1 \ldots n$, of the fuzzy sets of input linguistic terms $L T_{i j}$ :

$$
\mu_{i j}\left(z_{j}\right)=\exp \left[-\left(4 / r_{s}^{2}\right)\left(z_{j}-z_{i j}^{*}\right)^{2}\right], i=1 \ldots n_{R}, j=1 \ldots n,
$$

$z_{i j}^{*} i=1 \ldots n_{R}, j=1 \ldots n$, are the membership function centers, $\mathbf{p}_{1}^{*}$ in (7) is the first cluster center, $\mathbf{z}_{1}^{*}$ is the center of rule 1 and also the projection of $\mathbf{p}_{1}^{*}$ on axis $\mathbf{z}$ in terms of (1), and $P_{1}\left(\mathbf{p}_{1}^{*}\right)$ is the potential of $\mathbf{p}_{1}^{*}$.

Step 2. Data sample index $k$ is incremented, viz. replaced with $k+1$, and next data sample $\mathbf{p}_{k}$ that belongs to the input-output data set defined in (2) is read.

Step 3. The potential of each new data sample $P_{k}\left(\mathbf{p}_{k}\right)$ and the potentials of the centers $P_{k}\left(\mathbf{p}_{l}^{*}\right)$ of existing rules (clusters) with index $l$ are recursively updated as:

$$
\begin{aligned}
& P_{k}\left(\mathbf{p}_{k}\right)=(k-1) /\left[(k-1)\left(\vartheta_{k}+1\right)+\sigma_{k}-2 v_{k}\right], \\
& \vartheta_{k}=\sum_{j=1}^{n+1}\left(p_{k}^{j}\right)^{2}, \sigma_{k}=\sum_{j=1}^{n+1} \sum_{l=1}^{k-1}\left(p_{l}^{j}\right)^{2}, v_{k}=\sum_{j=1}^{n+1}\left(p_{k}^{j} \sum_{l=1}^{k-1} p_{l}^{j}\right), \\
& P_{k}\left(\mathbf{p}_{l}^{*}\right)=(k-1) P_{k-1}\left(\mathbf{p}_{l}^{*}\right) /\left[k-2+P_{k-1}\left(\mathbf{p}_{l}^{*}\right)+P_{k-1}\left(\mathbf{p}_{l}^{*}\right) \sum_{j=1}^{n+1}\left(d_{k(k-1)}^{j}\right)^{2}\right] .
\end{aligned}
$$

Step 4. The possible modification or upgrade of the rule base structure is carried out by means of the potential of the new data compared to the potential of the existing rules' centers. The rule base structure is modified if certain conditions mentioned in [22], [2734] are fulfilled.

Step 5. The parameters in the rule consequents are updated using either the Recursive Least Squares (RLS) algorithm or the weighted Recursive Least Squares (wRLS) algorithm. These updates result in updated vectors $\hat{\boldsymbol{\theta}}_{k}$ and $\mathbf{C}_{k}, k=2 \ldots D$.

Step 6. The output of evolving Takagi-Sugeno-Kang fuzzy model at next discrete time step $k+1$ is predicted as $\hat{y}_{k+1}$ :

$$
\hat{y}_{k+1}=\boldsymbol{\psi}_{k}^{T} \hat{\boldsymbol{\theta}}_{k},
$$

where the general expression of (10) and the expressions of the vectors are:

$$
\begin{aligned}
& y=\boldsymbol{\psi}^{T} \boldsymbol{\theta}, \boldsymbol{\theta}=\left[\begin{array}{llll}
\boldsymbol{\pi}_{1}^{T} & \boldsymbol{\pi}_{2}^{T} & \ldots & \boldsymbol{\pi}_{n_{R}}^{T}
\end{array}\right]^{T}, \\
& \boldsymbol{\psi}^{T}=\left[\begin{array}{lllll}
\lambda_{1}\left[\begin{array}{llll}
1 & \mathbf{z}^{T}
\end{array}\right] & \lambda_{2}\left[\begin{array}{lll}
1 & \mathbf{z}^{T}
\end{array}\right] & \ldots & \lambda_{n_{R}}\left[\begin{array}{l}
1 \\
\mathbf{z}^{T}
\end{array}\right]
\end{array}\right] .
\end{aligned}
$$

Step 7. The algorithm continues with step 2 until all data points of the input-output data set presented in expression (2) are read.

As emphasized in [31] and exemplified for a popular nature-inspired evolutionarybased optimization algorithm, RLS and wRLS in step 5 can be replaced with other optimization algorithms. Some classical and nature-inspired evolutionary-based algorithms and various applications subjected to optimization problems are presented in [53-64], with focus on Charged System Search and Gravitational Search algorithms.

Along with limiting model complexity, i.e., number of rules and parameters, to allow for model generalization, there is a need to limit minimal model complexity to avoid 
trivial solutions. A way of doing it is to insert the constraints related to the optimization problem solved in step 5 because providing adequate learning data is not sufficient. However, not only upper constraints but lower ones as well should be considered as, for example, using a simple model with just one rule could mean that the evolving TakagiSugeno-Kang fuzzy model is not a meaningful way of modeling the system.

\section{Two Automotive APPLICATIONS}

\subsection{Modeling the longitudinal slip in the anti-lock braking systems}

The continuous-time nonlinear state-space model of the ABS process is derived on the basis of [34] and [65]:

$$
\begin{aligned}
& J_{1} \dot{x}_{1}=F_{n} r_{1} \mu(\lambda)-d_{1} x_{1}-M_{10}-M_{1}, \\
& J_{2} \dot{x}_{2}=-F_{n} r_{2} \mu(\lambda)-d_{2} x_{2}-M_{20}, \\
& \dot{M}_{1}=c_{31}\left(b(u)-M_{1}\right),
\end{aligned}
$$

where $\lambda$ is longitudinal slip, $J_{1}$ and $J_{2}$ are inertia moments of the wheels shown in Fig. 2, $x_{1}$ and $x_{2}$ are angular velocities, $d_{1}$ and $d_{2}$ are friction coefficients in the axes of the wheels, $M_{10}$ and $M_{20}$ are the static friction torques that oppose the normal rotation, $M_{1}$ is the brake torque, $r_{1}$ and $r_{2}$ are the wheels radii, $F_{n}$ is the normal force that the upper wheel pushes upon the lower wheel, $\mu(\lambda)$ is the friction coefficient, $\dot{x}_{1}$ and $\dot{x}_{2}$ are angular accelerations of the wheels, $u$ is the control signal applied to the actuator, namely the direct current (DC) motor which drives the upper wheel, and the actuator's nonlinear model is reflected in the nonlinear map $b(u)$.

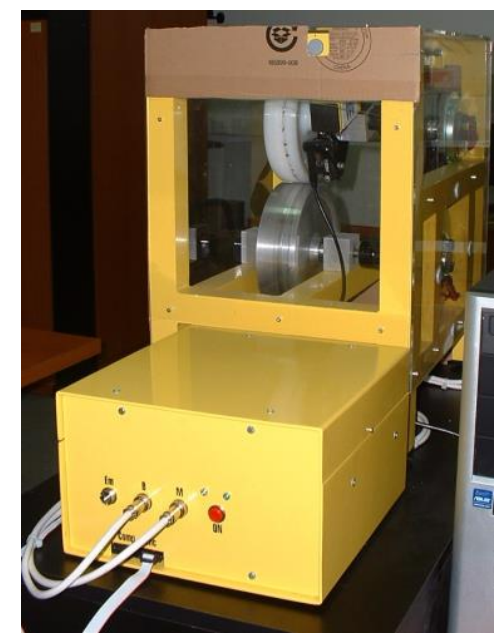

Fig. 2 ABS experimental setup in the Intelligent Control Systems Laboratory of the Politehnica University of Timisoara, Romania [65] 
Longitudinal $\operatorname{slip} \lambda$ is defined as:

$$
\lambda=\left(r_{2} x_{2}-r_{1} x_{1}\right) /\left(r_{2} x_{2}\right), x_{2} \neq 0,
$$

the controlled output of the ABS process is $\lambda$ if the longitudinal slip control is targeted, and notation $y=\lambda$ is employed in this sub-section in relation with the Takagi-SugenoKang fuzzy models presented in Section 2.

Setting the sampling period to $0.01 \mathrm{~s}$, several values of $u$ have been generated in order to cover different ranges of magnitudes and frequencies. Output $y=\lambda$ has been measured from the ABS equipment. The evolution of the system input versus time is presented in Fig. 3, which includes the input data for both training and validation (testing).
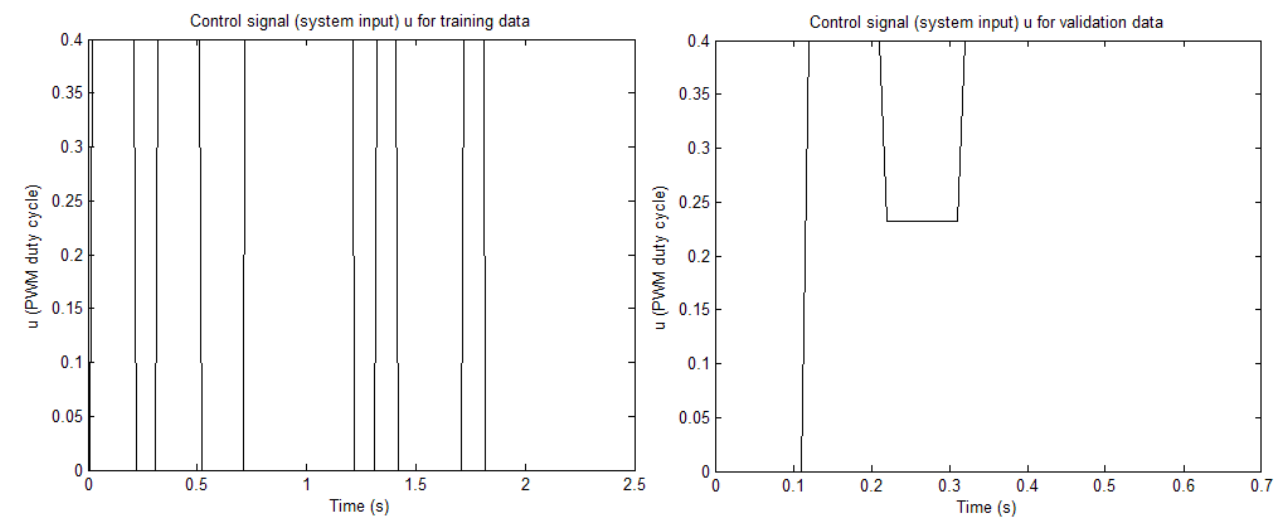

Fig. 3 ABS process inputs versus time expressed as training data and validation (testing) data [34]

The input signal illustrated in Fig. 3 has been applied to the laboratory equipment to generate input-output data points $\left(\mathbf{z}_{k}, y_{k}\right), k=1 \ldots D$, needed to be applied to the algorithm. Fig. 3 illustrates the inputs that correspond to the set of $D=240$ data points of the training data and the inputs of the other set of $D=60$ data points of the testing data. The output values computed by the Takagi-Sugeno-Kang fuzzy models and measured from the equipment will be next presented.

A part of the real-time experimental results is exemplified in Fig. 4 as the time responses of $y$ versus time of the Takagi-Sugeno-Kang fuzzy model with the input vector:

$$
\mathbf{z}_{k}=\left[\begin{array}{llll}
u_{k} & u_{k-1} & y_{k-1} & y_{k-2}
\end{array}\right]^{T},
$$

with wRLS applied in step 5 of the incremental online identification algorithm, and the real-world ABS. The response of the real-world ABS shown in Fig. 4 is one of the results of the real-time experiments on the laboratory equipment. 


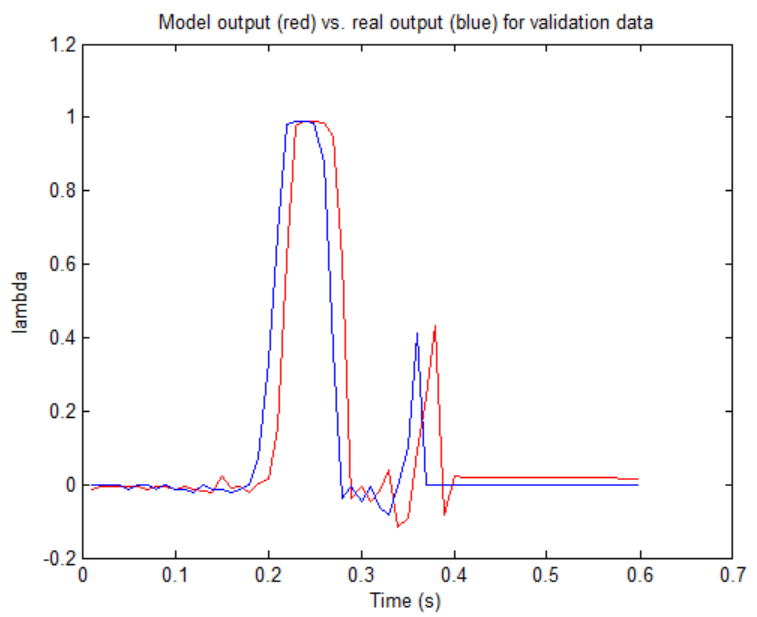

Fig. 4 Longitudinal slip position $y=\lambda$ versus time of the Takagi-Sugeno-Kang fuzzy model (red) and real-world ABS (blue) on the validation (testing) data set [34]

As shown in [34], this fuzzy model has evolved to 9 rules and has 117 identified parameters. The performance is acceptable; it can be improved but this is constrained by the number of data samples considered for this process. A reduced number of data samples have been used, so the mode complexity has an upper bound in order to allow for model generalization.

\subsection{Modeling of the vehicle speed in the vehicles with continuously variable transmission systems}

The nonlinear system represented by the vehicle with the CVT system is presented in [66] as a vehicular power train system, which consists of other sub-systems, i.e., the internal combustion engine, the torque converter, the CVT and the vehicle. The main equations which model these sub-systems are given as follows.

The internal combustion engine corresponds to a Honda Civic 1.6i SR $1598 \mathrm{cc}$ car, which produces $113 \mathrm{PS}$ DIN at $6300 \mathrm{rpm}$ and $143 \mathrm{Nm}$ of torque at $4800 \mathrm{rpm}$. The engine is also characterized by the moment of inertia $J_{\text {eng }}=0.284 \mathrm{~kg} \mathrm{~m}^{2}$ and the engine speed is constrained. The engine speed dynamics is modeled as an inertia system:

$$
\begin{aligned}
& J_{\text {eng }} \cdot \dot{\omega}_{\text {eng }}=T_{\text {eng }}-T_{c}, \\
& T_{\text {eng }}=\Gamma_{1}\left(\text { throttle }, \omega_{\text {eng }}\right)=\left[T_{\max }-\frac{T_{\max }-T_{p}}{\left(\omega_{P}-\omega_{M}\right)^{2}} \cdot\left(\omega_{\text {eng }}-\omega_{M}\right)^{2}\right] \cdot \text { throttle, } \\
& 0 \% \leq \text { throttle } \leq 100 \%,
\end{aligned}
$$

which indicates the nonlinear torque characteristic.

The torque converter (which consists of a pump, a turbine and a stator) is usually modeled by using the capacity factor/torque ratio versus speed ratio steady-state curves $\Gamma_{2}$ and $\Gamma_{3}$ given in the form of look-up tables. Data on such tables is given in [66]. 
The metallic V-belt driven CVT is dedicated to low-torque engine up to $200 \mathrm{Nm}$. This CVT is characterized by gear ratio $i_{C V T}$. The overall transmission equations are:

$$
\begin{aligned}
& i_{C V T}=\Gamma_{4}\left(v_{v}\right), \\
& T_{t r}=i_{C V T} \cdot i_{t q} \cdot T_{c}, \\
& T_{w}=i_{f r g} \cdot T_{t r}, \\
& \omega_{c}=i_{C V T} \cdot \omega_{w},
\end{aligned}
$$

where nonlinear map $\Gamma_{4}$ is given as a look-up table with the parameters presented in [66].

The vehicle is a compact hatchback weighting about $1200 \mathrm{~kg}$ and an equivalent rotational moment of inertia $J_{v e h}=150 \mathrm{~kg} \mathrm{~m}^{2}$, and the common size of the wheels is 15 " with 185/85 tires. The equations that characterize the vehicle dynamics are:

$$
\begin{aligned}
& J_{\text {veh }} \cdot \dot{\omega}_{w}=T_{w}-T_{\text {Drag }}-T_{\text {Roll }}, \\
& T_{\text {Drag }}=c \cdot \omega_{w}{ }^{2} \cdot \operatorname{sgn}\left(\omega_{w}\right), \\
& T_{\text {Roll }}=100+0.5 \cdot \omega_{w}, \\
& v_{v}=3.6 \cdot r_{w} \cdot \omega_{w} .
\end{aligned}
$$

Summing up the equations of the sub-systems using the structure, connection and parameters given in [66], the first principles model of the vehicle with CVT system is:

$$
\begin{aligned}
& \dot{x}_{1}=-32.47 \cdot 10^{-6} \cdot x_{1}^{2} \cdot u+0.225 \cdot x_{1} \cdot u-37.4 \cdot u-3.5 \cdot \frac{x_{1}^{2}}{\Gamma_{2}^{2}\left(x_{2} \cdot \Gamma_{4}\left(0.9 \cdot x_{2}\right), x_{1}\right)}, \\
& \dot{x}_{2}=0.03 \cdot \Gamma_{4}\left(0.9 \cdot x_{2}\right) \cdot \Gamma_{3}\left(x_{2} \cdot \Gamma_{4}\left(0.9 \cdot x_{2}\right), x_{1}\right) \cdot \frac{x_{1}^{2}}{\Gamma_{2}^{2}\left(x_{2} \cdot \Gamma_{4}\left(0.9 \cdot x_{2}\right), x_{1}\right)}, \\
& y=0.9 \cdot x_{2},
\end{aligned}
$$

where the characteristic variables are input variable $u=\operatorname{throttle}(\%)$, state variables $x_{1}=$ $\omega_{\text {eng }}$ and $x_{1}=\omega_{w}$, and the output variable represented by the vehicle speed $y=v_{v}(\mathrm{~km} / \mathrm{h})$. The nonlinear state-space model has been linearized in [66] around several operating points in order to allow for relatively simple controller designs.

Setting the sampling period to $0.1 \mathrm{~s}$, several values of $u$ have been generated in order to cover relatively wide ranges of magnitudes and frequencies. Output $y=v_{v}$ has been obtained as the response of the nonlinear state-space model, which is the first principles model given in (18). The evolution of the system input versus time is presented in Fig. 5, which includes the input data for both training and validation (testing).

The input signal illustrated in Fig. 5 has been applied to the system model given in (18) in order to generate input-output data points $\left(\mathbf{z}_{k}, y_{k}\right), k=1 \ldots D$, needed to be applied to the algorithm. Fig. 5 shows the inputs that correspond to the set of $D=3000$ data points of the training data and the inputs of the other set of $D=3000$ data points of the testing data. The output values computed by the Takagi-Sugeno-Kang fuzzy models and obtained as the response of the system model given in (18) will be next presented. 

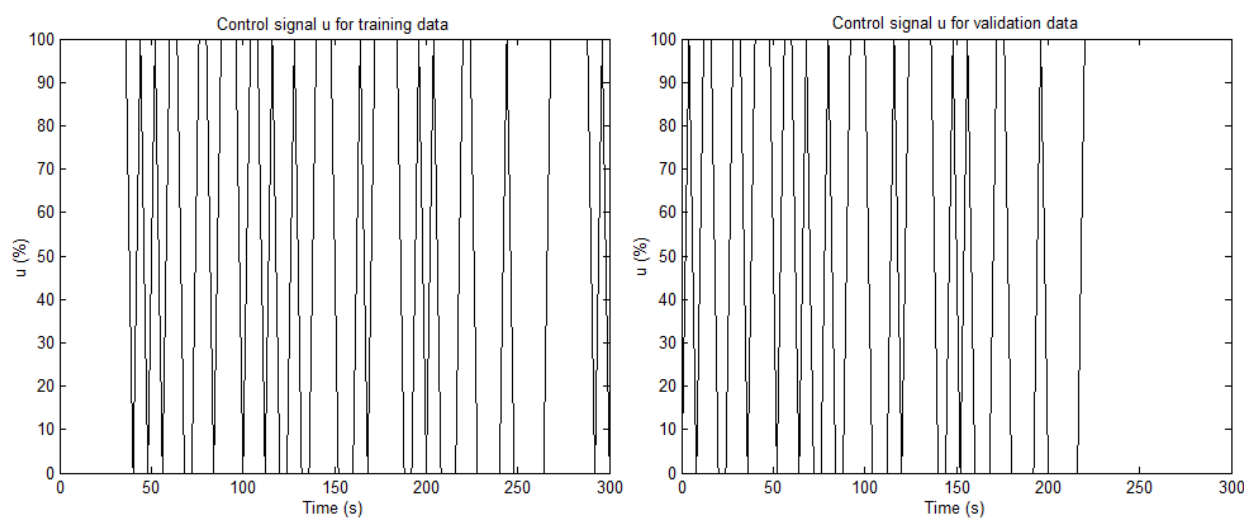

Fig. 5 Vehicle with CVT system inputs versus time expressed as training data and validation (testing) data

A part of the real-time experimental results is exemplified in Fig. 6 as the time responses of $y$ versus time of the Takagi-Sugeno-Kang fuzzy model with the input vector considered in (14), and the first principles model given in (18). The same input vector has been used as in the previous process model for the sake of simplicity. But the RLS has been applied for this automotive process application in step 5 of the incremental online identification algorithm.

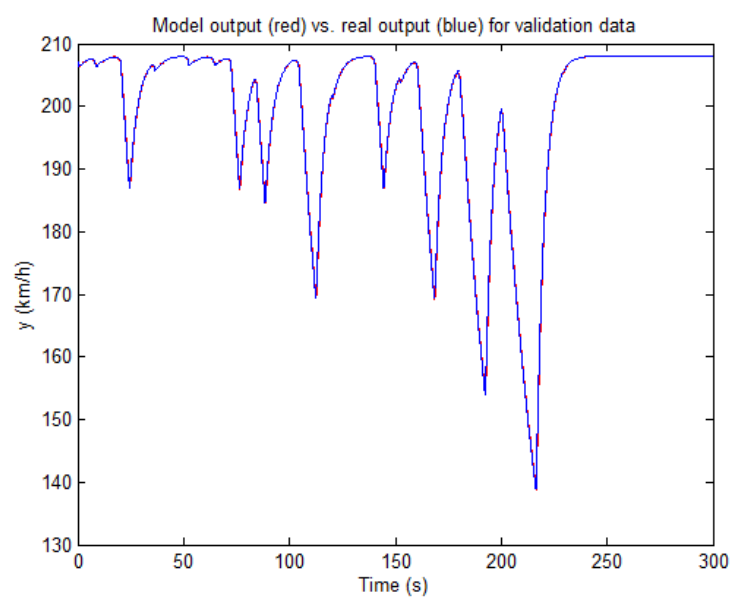

Fig. 6 Vehicle speed $y=v_{v}$ versus time of the Takagi-Sugeno-Kang fuzzy model (red) and real output (blue, i.e., output of first principles model) on the validation (testing) data set

This fuzzy model has evolved to 5 rules and has 65 identified parameters. The performance is very good although the number of parameters is rather small. Since the responses presented in Fig. 6 are very close, the zoomed responses are illustrated in Fig. 7. 


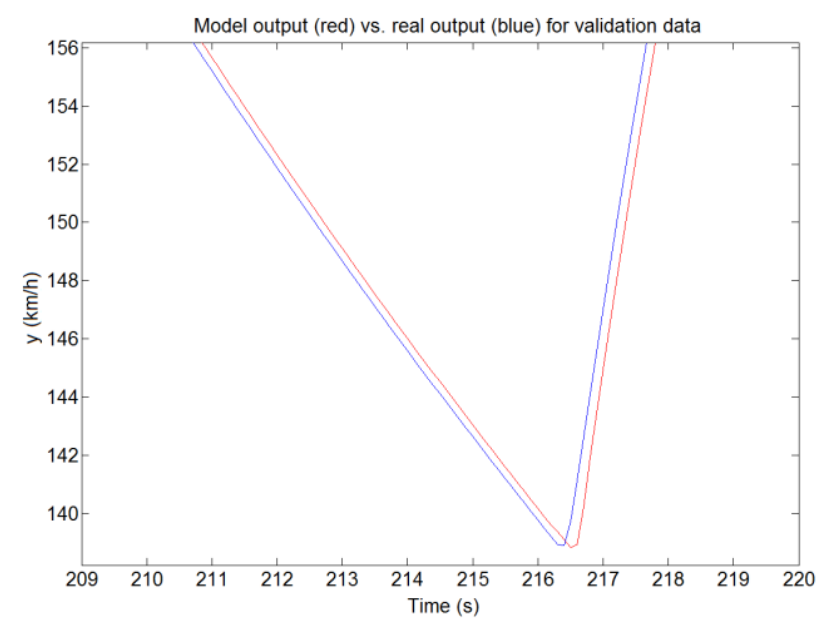

Fig. 7 Zoomed vehicle speed $y=v_{v}$ versus time of the Takagi-Sugeno-Kang fuzzy model (red) and real output (blue, i.e., output of first principles model) on a part of the validation (testing) data set

\section{CONCLUSIONS}

This paper has presented some results obtained by the Process Control group of the Politehnica University of Timisoara, Romania, in the application of evolving TakagiSugeno-Kang fuzzy models to two automotive process applications. A relatively simple incremental online identification algorithm, previously used by the authors in other nonlinear systems applications, has been applied to obtain the structure and parameters of the Takagi-Sugeno-Kang fuzzy models.

The main limitation of the models and the algorithm is the performance dependence on the parameters of the incremental online identification algorithm. This leads to parametric sensitivity and robustness problems, which can be solved by the proper definition and solving of optimization problems that include parametric sensitivity and robustness models related to the algorithm itself. The model-based fuzzy control of these automotive processes on the basis of evolving Takagi-Sugeno-Kang fuzzy models will be treated as a future research direction.

Acknowledgements: The research was supported by the grants of the Partnerships in priority areas - PN II program of the Executive Agency for Higher Education, Research, Development and Innovation Funding (UEFISCDI), project numbers PN-II-PT-PCCA-2013-4-0544 and PN-II-PTPCCA-2013-4-0070, and UEFISCDI, project number PN-II-RU-TE-2014-4-0207. 


\section{REFERENCES}

1. Sayed Mouchaweh, M., Devillez, A., Villermain Lecolier, G., Billaudel, P., 2002, Incremental learning in fuzzy pattern matching, Fuzzy Sets and Systems, 132(1), pp. 49-62.

2. Liu, P.X., Meng, M.Q.-H., 2004, Online data-driven fuzzy clustering with applications to real-time robotic tracking, IEEE Transactions on Fuzzy Systems, 12(3), pp. 516-523.

3. Wang, W., Vrbanek, Jr., J., 2008, An evolving fuzzy predictor for industrial applications, IEEE Transactions on Fuzzy Systems, 16(6), pp. 1439-1449.

4. Lughofer, E., 2011, Evolving fuzzy systems - Methodologies, advanced concepts and applications, SpringerVerlag, Berlin, Heidelberg.

5. Dovžan, D., Škrjanc, I., 2011, Recursive clustering based on a Gustafson-Kessel algorithm, Evolving Systems, 2(1), pp. 15-24.

6. Iglesias, J.A., Angelov, P., Ledezma, A., Sanchis, A., 2012, Creating evolving user behavior profiles automatically, IEEE Transactions on Knowledge and Data Engineering, 24(5), pp. 854-867.

7. Lughofer, E., 2013, On-line assurance of interpretability criteria in evolving fuzzy systems - Achievements, new concepts and open issues, Information Sciences, 251, pp. 22-46.

8. Precup, R.-E., Angelov, P., Costa, B.S.J., Sayed-Mouchaweh, M., 2015, An overview on fault diagnosis and nature-inspired optimal control of industrial process applications, Computers in Industry, 74, pp. 75-94.

9. Kangin, D., Angelov, P., Iglesias, J.A., 2016, Autonomously evolving classifier TEDAClass, Information Sciences, 366, pp. 1-11.

10. Za'in, C., Pratama, M., Lughofer, E., Anavatti, S.G., 2017, Evolving type-2 web news mining, Applied Soft Computing, 54, pp. 200-220.

11. Dovžan, D., Logar, V., Škrjanc, I., 2015, Implementation of an evolving Fuzzy Model (eFuMo) in a monitoring system for a waste-water treatment process, IEEE Transactions on Fuzzy Systems, 23(5), pp. 1761-1776.

12. Platt, J., 1991, A resource allocating network for function interpolation, Neural Computation, 3(2), pp. 213-225.

13. Ali, S.H.A., Ozawa, S., Ban, T., Nakazato, J., Shimamura, J., 2016, A neural network model for detecting DDoS attacks using darknet traffic features, Proc. 2016 International Joint Conference on Neural Networks, Vancouver, BC, Canada, pp. 2979-2985

14. Juang, C.-F., Lin, C.-T., 1998, An on-line self-constructing neural fuzzy inference network and its applications, IEEE Transactions on Fuzzy Systems, 6(1), pp. 12-32.

15. Prasad, M., Lin, C.-T., Li, D.-L., Hong, C.-T., Ding, W.-P., Chang, J.-Y., 2017, Soft-boosted self-constructing neural fuzzy inference network, IEEE Transactions on Systems, Man, and Cybernetics: Systems, 47(3), 584-588.

16. Tzafestas, S.G., Zikidis, K.C., 2001, NeuroFAST: On-line neuro-fuzzy ART-based structure and parameter learning TSK model, IEEE Transactions on Systems, Man, and Cybernetics, Part B: Cybernetics, 31(5), 797-802.

17. Tzafestas, S.G., Zikidis, K.C., 2002, NeuroFAST: high accuracy neuro-fuzzy modeling, Proc. 2002 IEEE International Conference on Artificial Intelligence Systems, Geelong, Australia, pp. 228-235.

18. Kasabov, N.K., Song, Q., 2002, DENFIS: Dynamic Evolving Neural-Fuzzy Inference System and its application for time-series prediction, IEEE Transactions on Fuzzy Systems, 10(2), pp. 144-154.

19. Riza, L.S., Bergmeir, C., Herrera, F., Benitez, J.M., 2014, Learning from data using the R package "FRBS", Proc. 2014 IEEE International Conference on Fuzzy Systems, Beijing, China, pp. 2149-2155.

20. Lin, F.-J., Lin, C.-H., Shen, P.-H., 2002, Self-constructing fuzzy neural network speed controller for permanentmagnet synchronous motor drive, IEEE Transactions on Fuzzy Systems, 9(5), pp. 751-759.

21. Wang, N., Er, M.J., 2015, Self-constructing adaptive robust fuzzy neural tracking control of surface vehicles with uncertainties and unknown disturbances, IEEE Transactions on Control Systems Technology, 23(3), pp. 991-1002.

22. Angelov, P., Filev, D., 2004, An approach to online identification of Takagi-Sugeno fuzzy models, IEEE Transactions on Systems, Man, and Cybernetics, Part B: Cybernetics, 34(1), pp. 484-498.

23. Moshtaghi, M., Bezdek, J.C., Leckie, C., Karunasekera, S., Palaniswami, M., 2015, Evolving fuzzy rules for anomaly detection in data streams, IEEE Transactions on Fuzzy Systems, 23(3), pp. 688-700.

24. Lughofer, E., Klement, E.P., 2005, FLEXFIS: A variant for incremental learning of Takagi-Sugeno fuzzy systems, Proc. $14^{\text {th }}$ IEEE International Conference on Fuzzy Systems, Reno, NV, USA, pp. 915-920.

25. Xie, B.-K., Lee, S.-J., 2014, A modified scheme for all-pairs evolving fuzzy classifiers, Proc. 2014 International Conference on Machine Learning and Cybernetics, Lanzhou, China, vol. 2, pp. 573-578.

26. Pratama, M., Anavatti, S.G., Angelov, P., Lughofer, E., 2014, PANFIS: A novel incremental learning machine, IEEE Transactions on Neural Networks and Learning Systems, 25(1), pp. 55-68. 
27. Precup, R.-E., Preitl, S., Bojan-Dragos, C.-A., Radac, M.-B., Szedlak-Stinean, A.-I., Hedrea, E.-L., Roman, R.C., 2016, Evolving Takagi-Sugeno fuzzy modeling applications of incremental online identification algorithms, Proc. XIII International SAUM Conference on Systems, Automatic Control and Measurements, Niš, Serbia, pp. $3-10$.

28. Precup, R.-E., Filip, H.-I., Radac, M.-B., Pozna, C., Dragos, C.-A., Preitl, S., 2012, Experimental results of evolving Takagi-Sugeno fuzzy models for a nonlinear benchmark, Proc. 2012 IEEE ${ }^{\text {rd }}$ International Conference on Cognitive Infocommunications, Kosice, Slovakia, pp. 567-572.

29. Precup, R.-E., Filip, H.-I., Radac, Petriu, E.M., Preitl, S., Dragos, C.-A., 2014, Online identification of evolving Takagi-Sugeno-Kang fuzzy models for crane systems, Applied Soft Computing, 24, pp. 1155-1163.

30. Precup, R.-E., Voisan, E.-I., Petriu, E.M., Radac, M.-B., Fedorovici, L.-O., 2015, Implementation of evolving fuzzy models of a nonlinear process, Proc. $12^{\text {th }}$ International Conference on Informatics in Control, Automation and Robotics, Colmar, France, vol. 1, pp. 5-14.

31. Precup, R.-E., Voisan, E.-I., Petriu, E.M., Radac, M.-B., Fedorovici, L.-O., 2016, Gravitational search algorithm-based evolving fuzzy models of a nonlinear process, in: Informatics in Control, Automation and Robotics, Filipe, J., Madani, K., Gusikhin, O., Sasiadek, J. (eds.), Springer International Publishing, Cha,: Lecture Notes in Electrical Engineering, vol. 383, pp. 51-62.

32. Precup, R.-E., Teban, T.-A., Alves de Oliveira, T.E., Petriu, E.M., 2016, Evolving fuzzy models for myoelectricbased control of a prosthetic hand, Proc. 2016 IEEE International Conference on Fuzzy Systems, Vancouver, BC, Canada, pp. 72-77.

33. Precup, R.-E., Radac, M.-B., Petriu, E.M., Roman, R.-C., Teban, T.-A., Szedlak-Stinean, A.-I., 2016, Evolving fuzzy models for the position control of twin rotor aerodynamic systems, Proc. 2016 IEEE $14^{\text {th }}$ International Conference on Industrial Informatics, Poitiers, France, pp. 237-242.

34. Precup, R.-E., Bojan-Dragos, C.-A., Hedrea, E.-L., Borlea, I.-D., Petriu, E.M., 2017, Evolving fuzzy models for anti-lock braking systems, Proc. 2017 IEEE International Conference on Computational Intelligence and Virtual Environments for Measurement Systems and Applications, Annecy, France, pp. 1-6.

35. Preitl, S., Precup, R.-E., 1996, On the algorithmic design of a class of control systems based on providing the symmetry of open-loop Bode plots, Scientific Bulletin of UPT, Transactions on Automatic Control and Computer Science, 41(2), pp. 47-55.

36. Precup, R.-E., Preitl, S., 1997, Popov-type stability analysis method for fuzzy control systems, Proc. Fifth European Congress on Intelligent Technologies and Soft Computing, Aachen, Germany, vol. 2, pp. 1306-1310.

37. Škrjanc, I., Blažič, S., Matko, D., 2002, Direct fuzzy model-reference adaptive control, International Journal of Intelligent Systems, 17(10), pp. 943-963.

38. Baranyi, P., 2004, TP model transformation as a way to LMI-based controller design, IEEE Transactions on Industrial Electronics, 51(2), pp. 387-400.

39. Milosavljević, Č., Peruničić-Draženović, B., Veselić, B., Mitić, D., 2007, A new design of servomechanism with digital sliding mode, Electrical Engineering, 89(3), pp. 233-244.

40. Filip, F.G., 2008, Decision support and control for large-scale complex systems, Annual Reviews in Control, 32(1), pp. 61-70.

41. Antić, D., Milojković, M., Jovanović, Z., Nikolić, S., 2010, Optimal design of the fuzzy sliding mode control for a DC servo drive, Strojniški vestnik - Journal of Mechanical Engineering, 56(7-8), pp. 455-463.

42. Sánchez Boza, A., Haber Guerra, R., Gajate, A., 2011, Artificial cognitive control system based on the shared circuits model of sociocognitive capacities. A first approach, Engineering Applications of Artificial Intelligence, 24(2), pp. 209-219.

43. Pozna, C., Minculete, N., Precup, R.-E., Kóczy, L.T., Ballagi, Á., 2012, Signatures: Definitions, operators and applications to fuzzy modeling, Fuzzy Sets and Systems, 201, pp. 86-104.

44. Precup, R.-E., Doboli, S., Preitl, S., 2000, Stability analysis and development of a class of fuzzy control systems, Engineering Applications of Artificial Intelligence, 13(3), pp. 237-247.

45. Nikolić, S., Antić, D., Danković, B., Milojković, M., Jovanović, Z., Perić, S., 2010, Orthogonal functions applied in antenna positioning, Advances in Electrical and Computer Engineering, 10(4), pp. 35-42.

46. Vašćák, J., Hirota, K., 2011, Integrated decision-making system for robot soccer, Journal of Advanced Computational Intelligence and Intelligent Informatics, 15(2), pp. 156-163.

47. Chiou, J.-S., Tsai, S.-H., 2012, Stability and stabilization of Takagi-Sugeno fuzzy switched system with timedelay, Proceedings of the Institution of Mechanical Engineers, Part I: Journal of Systems and Control Engineering, 226(5), pp. 615-621.

48. Horváth, L., Rudas, I.J., 2013, Active knowledge for the situation-driven control of product definition, Acta Polytechnica Hungarica, 10(2), pp. 217-234. 
49. Milosavljević, Č., Peruničić-Draženović, B., Veselić, B., 2013, Discrete-time velocity servo system design using sliding mode control approach with disturbance compensation, IEEE Transactions on Industrial Informatics, 9(2), pp. 920-927.

50. Derr, K.W., Manic, M., 2015, Wireless sensor networks - node localization for various industry problems, IEEE Transactions on Industrial Informatics, 11(3), pp. 752-762.

51. Ramos, J.V., Dourado, A., 2004, On line interpretability by rule base simplification and reduction, Proc. European Symposium on Intelligent Technologies, Hybrid Systems and Their Implementation on Smart Adaptive Systems EUNITE 2004, Aachen, Germany, pp. 1-6.

52. Aires, L., Araújo, J., Dourado, A., 2009, Industrial monitoring by evolving fuzzy systems, Proc. Joint 2009 IFSA World Congress and 2009 EUSFLAT Conference, Lisbon, Portugal, pp. 1358-1363.

53. Precup, R.-E., David, R.-C., Petriu, E.M., Preitl, S., Radac, M.-B., 2014, Novel adaptive charged system search algorithm for optimal tuning of fuzzy controllers, Expert Systems with Applications, 41(4), pp. 1168-1175.

54. Arsene, O., Dumitrache, I., Mihu, I., 2015, Expert system for medicine diagnosis using software agents, Expert Systems with Applications, 42(4), 1825-1834.

55. Precup, R.-E., Sabau, M.-C., Petriu, E.M., 2015, Nature-inspired optimal tuning of input membership functions of Takagi-Sugeno-Kang fuzzy models for anti-lock braking systems, Applied Soft Computing, 27, 575-589.

56. Kazakov, A.L., Lempert, A.A., 2015, On mathematical models for optimization problem of logistics infrastructure, International Journal of Artificial Intelligence, 13(1), pp. 200-210.

57. Moharam, A., El-Hosseini, M.A., Ali, H.A., 2015, Design of optimal PID controller using NSGA-II algorithm and level diagram, Studies in Informatics and Control, 24(3), pp. 301-308.

58. Osaba, E., Onieva, E., Dia, F., Carballedo, R., Lopez, P., Perallos, A., 2015, A migration strategy for distributed evolutionary algorithms based on stopping non-promising subpopulations: A case study on routing problems, International Journal of Artificial Intelligence, 13(2), 46-56.

59. Ć́ojbašić, Ž., Nikolić, V., Petrović, E., Pavlović, V., Tomić, M., Pavlović, I., Ćirić, I., 2014, A real time neural network based finite element analysis of shell structure, Facta Universitatis, Series: Mechanical Engineering 12(2), pp. 149-155.

60. Tar, J.K., Bitó, J.F., Rudas, I.J., 2016, Contradiction resolution in the adaptive control of underactuated mechanical systems evading the framework of optimal controllers, Acta Polytehnica Hungarica, 13(1), pp. 97-121.

61. Castro, J.R., Castillo, O., Sanchez, M.A., Mendoza, O., Rodríguez Díaz, A., Melin, P., 2016, Method for higher order polynomial Sugeno fuzzy inference systems, Information Sciences, 351, pp. 76-89.

62. Qin, Q., Cheng, S., Zhang, Q., Li, L., Shi, Y., 2016, Particle swarm optimization with interswarm interactive learning strategy, IEEE Transactions on Cybernetics, 46(10), pp. 2238-2251.

63. Solos, I.P., Tassopoulos, I.X., Beligiannis, G.N., 2016, Optimizing shift scheduling for tank trucks using an effective stochastic variable neighbourhood approach, International Journal of Artificial Intelligence, 14(1), pp. $1-26$.

64. Fakharian, A., Rahmani, R., 2016, An optimal controlling approach for voltage regulation and frequency stabilization in islanded microgrid system, Control Engineering and Applied Informatics, 18(4), 107-114.

65. Precup, R.-E., Sabau, M.-C., Dragos, C.-A., Radac, M.-B., Fedorovici, L.-O., Petriu, E.M., 2014, Particle swarm optimization of fuzzy models for anti-lock braking systems, Proc. 2014 IEEE Conference on Evolving and Adaptive Intelligent Systems, Linz, Austria, pp. 1-6.

66. Dragos, C.-A., Preitl, S., Precup, R.-E., Pirlea, D., Nes, C.-S., Petriu E.M., Pozna, C., 2010, Modeling of a vehicle with continuously variable transmission, Proc. $19^{\text {th }}$ International Workshop on Robotics in Alpe-AdriaDanube Region, Budapest, Hungary, pp. 441-446. 